Revista Brasil. Bot., V.31, n.2, p.309-315, abr.-jun. 2008

\title{
Padrões de reprodução vegetativa em espécies de Lejeuneaceae (Marchantiophyta) e seu significado taxonômico e ecológico
}

\author{
CID JOSÉ PASSOS BASTOS ${ }^{1,2}$
}

(recebido: 02 de agosto de 2007; aceito: 08 de maio de 2008)

\begin{abstract}
Vegetative reproduction patterns in species of Lejeuneaceae (Marchantiophyta) and its taxonomic and ecological significances). The study of the vegetative reproduction of 33 infrageneric taxa of Lejeuneaceae from the State of Bahia (Brazil) allowed the identification of six basic patterns of the vegetative reproduction process: (a) cladia; (b) leaves fragmentation; (c) regenerates; (d) caducous leaves; (e) gemmae; (f) semi-caducous underleaves. The employment of the vegetative reproduction patterns to evaluate phylogenetic relationships is not recommended, since it is present in various taxa not closely related.
\end{abstract}

Key words - gemmae, Lejeuneaceae, Marchantiophyta, propagules, vegetative reproduction

RESUMO - (Padrões de reprodução vegetativa em espécies de Lejeuneaceae (Marchantiophyta) e seu significado taxonômico e ecológico). O estudo da reprodução vegetativa de 33 táxons infragenéricos de Lejeuneaceae, ocorrentes no Estado da Bahia (Brasil), permitiu a identificação de seis padrões básicos de processos de reprodução vegetativa: (a) produção de cládios; (b) fragmentação de filídios; (c) produção de regenerantes; (d) filídios caducos; (e) produção de gemas; (f) anfigastros semi-caducos. O emprego do padrão de reprodução vegetativa para avaliar as relações filogenéticas dos táxons não é recomendado, uma vez que está presente em vários táxons não estreitamente relacionados.

Palavras-chave - gemas, Lejeuneaceae, Marchantiophyta, propágulos, reprodução vegetativa

\section{Introdução}

A reprodução vegetativa é um fenômeno amplamente distribuído entre as briófitas, sendo que a ocorrência desse processo na fase gametofítica o torna único entre as plantas terrestres.

Vários estudos efetuados em diferentes espécies e épocas trataram da propagação vegetativa em briófitas, podendo-se citar Fulford (1944), Mishler (1988), Schuster (1988), Kimmerer (1991, 1994), Newton \& Mishler (1994), Reiner-Drehwald (1994), Reese (1997, 2001a, b), Laaka-Lindberg (1999, 2000), Martin (2001), Roads \& Longton (2003), Nordhorn-Richter (2004) e Pfeiffer et al. (2006). Dentre esses, Fulford (1994) tratou especificamente de Ceratolejeunea Jack \& Steph., um membro da família Lejeuneaceae. No Brasil não consta na literatura nenhum estudo sobre processos de reprodução vegetativa em hepáticas folhosas e nem para musgos.

A ocorrência de reprodução vegetativa está amplamente distribuída entre diversos táxons de Lejeuneaceae, os quais nem sempre estreitamente relacionados, e vários autores, incluindo Schuster (1980, 2000) referem os processos de reprodução vegetativa como um critério taxonômico. A não observação de

\footnotetext{
1 Universidade Federal da Bahia, Instituto de Biologia, Departamento de Botânica, Laboratório de Taxonomia de Briófitas. Campus de Ondina, 40170-280 Salvador, Bahia, Brasil

2 Autor para correspondência: cjpbasto@ufba.br
}

reprodução vegetativa em um dado táxon, não implica que ela não possa ocorrer, sob determinadas condições ou ambientes. Como são dependentes de água para se reproduzirem sexuadamente, as briófitas para se dispersarem têm que utilizar outros meios que lhes sejam viáveis e favoráveis a uma rápida ocupação do hábitat. E um desses meios é a produção de diásporos vegetativos.

As briófitas, por sua complexidade reprodutiva e morfológica, não produzem mitósporos, como fazem as algas e certos fungos e, dessa forma, a fragmentação do gametófito e a produção de gemas ou propágulos exercem a mesma função, ou seja, dispersão por reprodução vegetativa. Isso lhes faculta ocupar habitats relativamente áridos, ou aqueles em que a disponibilidade de água seja irregular, uma vez que o processo de fecundação necessita de água para ocorrer. Entre as hepáticas, a ocorrência de reprodução vegetativa, seja por gemas ou fragmentação do gametófito, é muito comum, e entre as Lejeuneaceae podem ser observados vários padrões que são repetidos em diversos táxons não relacionados. O objetivo do trabalho é identificar os diversos padrões de reprodução vegetativa que ocorrem entre os membros de Lejeuneaceae, e discutir os aspectos taxonômicos e ecológicos dessa ocorrência.

\section{Material e métodos}

As estruturas de reprodução vegetativa foram identificadas ao longo dos estudos sobre as Lejeuneaceae ocorrentes no 
Estado da Bahia, para o que foram examinados $c a .1 .444$ espécimes distribuídos em 39 gêneros e 120 espécies, procedentes de coletas realizadas em várias localidades e depositados nos Herbários ALCB, CEPEC, HUEFS, SP, NY, G, e J (siglas de acordo com Holmgren et al. 1990). A nomenclatura foi adaptada de Gradstein (1994), Gradstein et al. (2003) e Schuster (1980).

\section{Resultados}

Foram observados processos de reprodução vegetativa em 33 táxons infragenéricos (tabela 1), pertencentes às subfamílias Ptychanthoideae e Lejeuneoideae.

Foram detectados os seguintes padrões de reprodução vegetativa (tabela 1): 1) Fragmentação de ramos através de produção de cládios (figura 1), que são: ramos, em geral reduzidos, que se desprendem facilmente do caulídio principal. Pode ser identificado pela persistência do colar do ramo tipo-Lejeunea após a queda do ramo (figura 2). Os ramos assim dispersos podem regenerar novos gametófitos adultos, aumentando o número de indivíduos na população. 2) Fragmentação de filídios: fragmentos destacados da margem do filídio que originam regenerantes de novos gametófitos. 3) Produção de regenerantes (figuras 5-6): os regenerantes são pequenas plântulas originadas a partir de células da margem ou da lâmina do filídio, seja em filídios persistentes, seja em filídios caducos. 4) Filídios caducos (figuras 3-4): que podem ocorrer em diversos padrões; aqueles que apenas são destacados, os que são destacados e apresentam rizóides na margem (figura 4), os que apresentam gemas e aqueles que apresentam regenerantes (figura 5), tanto na margem quanto na lâmina, e ainda

Tabela 1. Padrões de reprodução vegetativa observados em espécies de Lejeuneaceae encontradas no Estado da Bahia, Brasil.

Table 1. Vegetative reproduction patterns observed in Lejeuneaceae species from Bahia State, Brazil.

Táxons

Sub-Família Ptychantoideae

Tribo Ptychantheae

Archilejeunea fuscescens (Hampe ex Lehm.) Fulford

Caudalejeunea lehmanniana (Gottsche) A. Evans

Schiffneriolejeunea polycarpa (Nees) Gradst.

Sub-Família Lejeuneoideae

Tribo Lejeuneeae

Aphanolejeunea truncatifolia Horik.

Aphanolejeunea paucifolia (Spruce) E. Reiner

Ceratolejeunea cornuta (Lindenb.) Steph.

Ceratolejeunea laetefusca (Austin) R.M. Schust.

Cheilolejeunea adnata (Kunze) Grolle

Cheilolejeunea oncophylla (Ångstr.) Grolle \& E. Reiner

Cheilolejeunea rigidula (Mont.) R.M. Schust.

Cheilolejeunea trifaria (Reinw. et al.) Muzut.

Cololejeunea cardiocarpa (Mont.) A. Evans

Cololejeunea minutissima (Smith) Schiffn. ssp. minutissima

Cololejeunea minutissima (Smith) Schiffn. ssp. myriocarpa (Nees \& Mont.) R.M. Schust.

Colura cylindrica Herzog

Cyclolejeunea convexistipa (Lehm. \& Lindenb.) A. Evans
Padrões

Gemas talóides irregulares, na superfície do filídio

Gemas discóides, sem células adesivas

Gemas talóides alongadas a irregulares, na superfície do filídio

Gemas talóides discóides com células adesivas

Gemas discóides com células adesivas

Produção de regenerantes a partir de células laminares

Gemas talóides alongadas a irregulares, na margem do filídio

Filídios caducos sem rizóides marginais

Filídios caducos com rizóides marginais

Fragmentação de ramos (cládios)

Filídios caducos sem rizóides marginais

Produção de regenerantes a partir de células laminares

Produção de regenerantes a partir de células laminares

Gemas discóides na superfície do filídio, sem células adesivas

Gemas discóides na superfície do filídio, sem células adesivas

Gemas discóides na superfície do filídio, sem células adesivas

Gemas discóides na superfície do filídio, sem células adesivas Gemas discóides na superfície do filídio, sem células adesivas 
continuação

\begin{tabular}{|c|c|}
\hline Táxons & Padrões \\
\hline Diplasolejeunea brunea Steph. & Gemas discóides na superfície do filídio, sem células adesivas \\
\hline Lejeunea cancellata Nees \& Mont. & Fragmentação de ramos (cládios) \\
\hline Lejeunea elliottii Spruce & Fragmentação de filídios \\
\hline Cyclolejeunea luteola (Spruce) Grolle & Gemas talóides alongadas a irregulares, na margem do filídio \\
\hline Lejeunea huctumalcensis Lindenb. \& Gottsche & Gemas talóides alongadas formadas na margem do filídio \\
\hline Lejeunea maxonii (A. Evans) X.-L. He & $\begin{array}{l}\text { Filídios caducos sem rizóides na margem } \\
\text { Produção de regenerantes a partir de células da margem }\end{array}$ \\
\hline Lejeunea phyllobola Nees \& Mont. & $\begin{array}{l}\text { Filídios caducos com gemas } \\
\text { Produção de regenerantes a partir de células da margem }\end{array}$ \\
\hline Lejeunea ptosimophylla C. Massal. & Anfigastro semi-caduco \\
\hline Lejeunea tapajosensis Spruce & $\begin{array}{l}\text { Filídios caducos, sem rizóides e sem gemas } \\
\text { Produção de regenerantes a partir de células da margem }\end{array}$ \\
\hline Lepidolejeunea involuta (Gottsche) Grolle & Filídios caducos sem rizóides na margem \\
\hline Leucolejeunea caducifolia Gradst. \& Schäffer-Verwimp & Filídios caducos sem rizóides na margem \\
\hline Microlejeunea epiphylla Bischl. & Fragmentação de ramos (cládios) \\
\hline Prionolejeunea galliotii Steph. & Gemas talóides alongadas a irregulares, na margem do filídio \\
\hline Rectolejeunea berteroana (Gottsche ex Steph.) A. Evans & Filídios caducos com rizóides na margem \\
\hline $\begin{array}{l}\text { Rectolejeunea emarginuliflora (Gottsche ex Steph.) } \\
\text { A. Evans }\end{array}$ & Filídios caducos com gemas talóides alongadas na margem \\
\hline Rectolejeunea flagelliformis A. Evans & $\begin{array}{l}\text { Filídios caducos com forma distinta dos persistentes, com } \\
\text { cílios na margem }\end{array}$ \\
\hline Schiffneriolejeunea polycarpa (Nees) Grolle & Gemas talóides irregulares na superfície do filídio \\
\hline Trachylejeunea aneogyna (Spruce) Grolle & Filídios caducos com rizóides na margem \\
\hline
\end{tabular}

os que têm forma distinta dos filídios persistentes, portando cílios na margem (figura 3 ). Em todos os casos, os filídios caducos podem regenerar novos gametófitos adultos a partir do desenvolvimento de regenerantes. 5) Produção de gemas (figuras 7-9): as gemas são pequenas estruturas pluricelulares originadas da margem ou da lâmina de filídios, as quais podem ser talóides alongadas (figura 7) ou irregulares (figura 11), ou discóides (figura 9-10). Podem se desenvolver na margem e superfície dos filídios. 6) Anfigastro semi-caduco (figura 12): ocorre em anfigastros bífidos e caracteriza-se pelo desprendimento de metade do anfigastro (um lobo), ficando a outra metade (o outro lobo) presa ao caulídio.

\section{Discussão}

O sucesso evolutivo de um ser vivo está relacionado com a sua capacidade de se multiplicar, dispersar, ocupar e se estabelecer em um habitat, desenvolvendo meios eficientes para o aproveitamento dos recursos que esse habitat oferece. Aliado ao processo sexuado, que permite maior variabilidade genética, está o assexuado, que ocorre de diversos modos e permite uma rápida ocupação do habitat.

Os processos de multiplicação ou propagação vegetativa têm sido referidos como de significado adaptativo a condições específicas do meio ambiente, onde o custo energético do processo sexuado é alto e, portanto, desvantajoso. Schuster (1988) discutindo o significado adaptativo da propagação vegetativa em conexão com as condições climáticas, refere que a frequiência e a diversidade de propagação vegetativa são mais reduzidas nos trópicos que nas regiões árticas e alpinas. É realmente plausível que condições de maior intensidade luminosa e baixa disponibilidade de água favoreçam mais a tendência de propagação vegetativa do que o processo sexuado, uma vez que esse último está na dependência direta de água. Também em ambientes instáveis ou em áreas sujeitas a forte interferência antrópica, tais como áreas urbanas e industriais, o processo de reprodução vegetativa está mais bem distribuído. Assim, os processos de reprodução vegetativa funcionariam como um "sistema de segurança" (Laaka-Lindberg 2000) para a produção de novos indivíduos, considerando as dificuldades para 

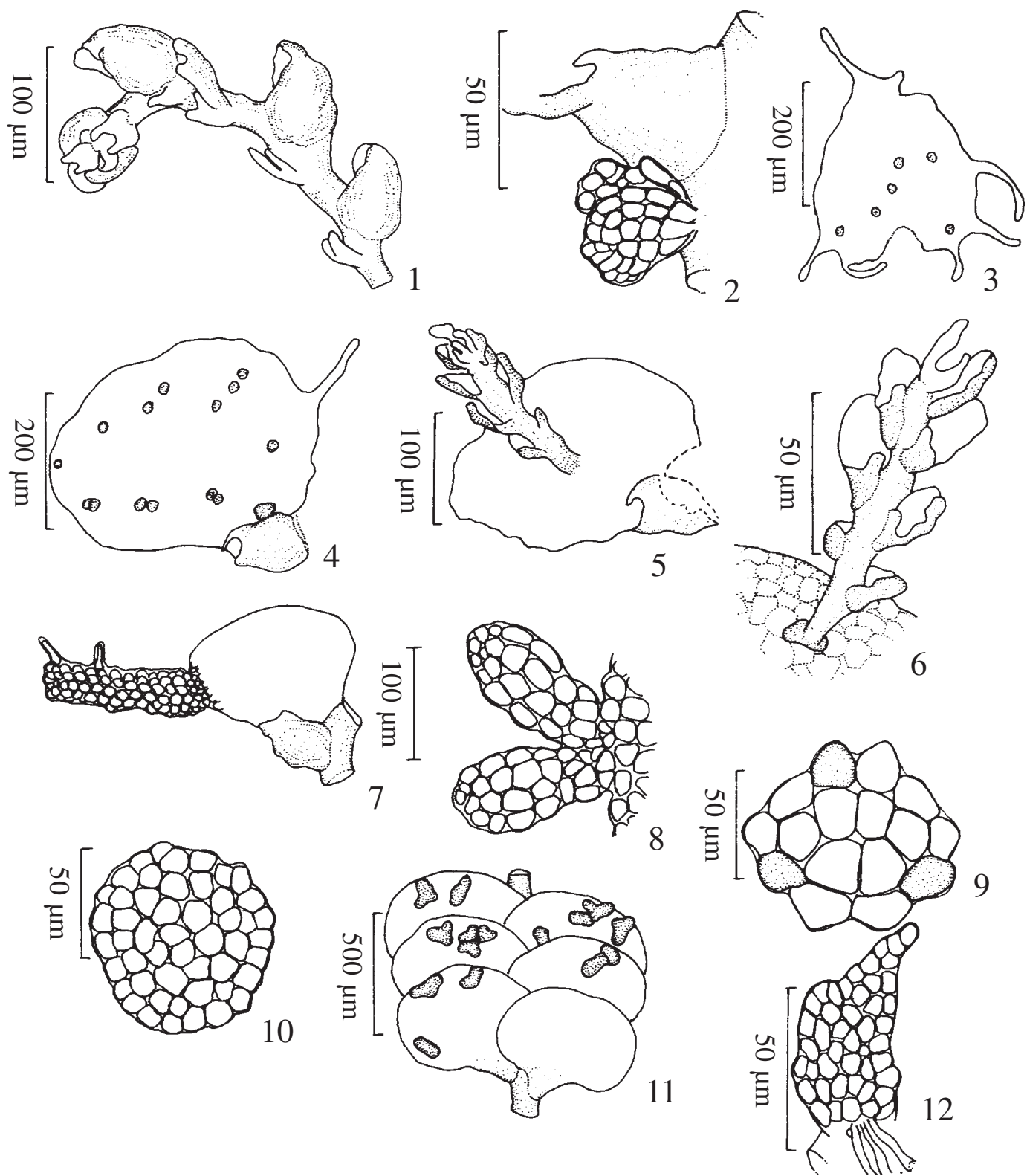

Figuras 1-12. Estruturas de reprodução vegetativa observadas em espécies de Lejeuneaceae. 1. Ramo caduco (cládio), de Lejeunea cancellata Nees \& Mont. 2. Colar basal do ramo caduco do tipo-Lejeunea, de L. cancellata. 3. Filídio caduco anômalo com cílios e rizóides na margem, de Rectolejeunea flagelliformis. 4. Filídio caduco normal, com rizóides na margem (vista ventral), de Rectolejeunea berteroana. 5. Filídio caduco com regenerante (vista ventral), de Lejeunea sp. 6. Regenerante de Ceratolejeunea cornuta. 7. Filídio com gema talóide alongada, de Cyclolejeunea luteola. 8. Gemas talóides marginais, de Lejeunea huctumalcensis. 9. Gema discóide com células adesivas de Aphanolejeunea truncatifolia. 10. Gema discóide sem células adesivas, de Caudalejeunea lehmanniana. 11. Gemas irregulares sobre a superfície dorsal dos filídios em Archilejeunea fuscescens. 12. Anfigastro semi-caduco de Lejeunea ptosimophylla.

Figures 1-12. Vegetative reproduction structures observed in Lejeuneaceae species. 1. Caducous branche (cladium) from Lejeunea cancellata Nees \& Mont. 2. Basal collar of the Lejeunea-type branche from L. cancellata. 3. Anomalous caducous leaf with marginal cilia and rhizoids, from Rectolejeunea flagelliformis. 4. Normal caducous leaf with marginal rhizoid from Rectolejeunea berteroana. 5. Caducous leaf with regenerate (ventral view) from Lejeunea sp. 6. Regenerate from Ceratolejeunea cornuta. 7. Leaf with elongated thalloid gemmae, from Cyclolejeunea luteola. 8. Marginal thalloid gemmae from Lejeunea huctumalcensis. 9. Discoid gemma with adhesive cells from Aphanolejeunea truncatifolia. 10. Discoid gemma without adhesives cells from Caudalejeunea lehmanniana. 11. Irregular thalloid gemmae on the leaf surface from Archilejeunea fuscescens. 12. Semi-caducous underleaf from Lejeunea ptosimophylla. 
que ocorra o processo sexuado. No entanto, observa-se ampla ocorrência de processos de reprodução vegetativa em floresta ombrófilas, no sub-bosque, em que as condições de umidade e luminosidade são mais estáveis.

Existe na literatura certa diferença de conceito entre o que seria reprodução assexual e reprodução vegetativa. Segundo alguns autores (Laaka-Lindberg 2000), o termo reprodução assexuada deveria ser reservado ao processo de formação de gemas a partir de células-mãe da gema, que funcionariam como equivalentes aos zigotos, enquanto que os processos de fragmentação e formação de ramos seriam meramente considerados como crescimento vegetativo. No entanto, algumas considerações podem ser feitas. Crescimento está relacionado à incorporação e ao aumento de matéria orgânica (massa), por um indivíduo em um dado intervalo de tempo, o que resultaria em um aumento proporcional do corpo desse indivíduo. Reprodução vegetativa, seja qual for o meio, representa o aumento do número de indivíduos, e não o de sua massa corpórea. Poder-se-ia argumentar que, no caso das briófitas que têm estrutura clonal agrupada em colônias, esses conceitos estariam quase que superpostos, pois o aumento do número de indivíduos resultaria no aumento equivalente do tamanho da colônia. Mesmo assim, cada indivíduo da colônia representa uma individualidade, não necessariamente um clone, pois não há certeza de que todos os indivíduos sejam derivados de um mesmo meiósporo. O modo como esses indivíduos se propagam, seja por formação de gemas seja por fragmentação, representa a formação de novos indivíduos, e não o aumento de massa corpórea de cada um individualmente. Assim, o termo "crescimento vegetativo" não parece ser adequado. Talvez fosse mais correto se aplicar o termo "fragmentação" para os processos de formação de cládios e filídios caducos, enquanto o termo "reprodução assexuada" unicamente para a formação de gemas e de regenerantes. Mas, de modo geral, considera-se a reprodução vegetativa s.l. (ou assexuada) dividida em dois tipos básicos (Pfeiffer et al. 2006): (a) reprodução vegetativa s.s., aquela que ocorre através de formação de gemas, propágulos ou plântulas; (b) reprodução clonal, aquela que ocorre por fragmentação de ramos (cládios) ou de partes da planta (do filídio, por exemplo).

Longton \& Schuster (1983) reportaram seis processos básicos de reprodução vegetativa: (a) formação de múltiplos gametófitos a partir de protonemas; (b) deterioração de partes velhas do gametófito com separação das partes mais jovens; (c) desenvolvimento de múltiplos gametófitos a partir de estolões; (d) desenvolvimento de gametófitos a partir de rizóides; (e) regeneração a partir de regenerantes; (f) produção de propágulos especializados. Glime (2007), entretanto, analisa dois processos gerais, além de analisar o modo de dispersão: fragmentação (de filídios e ramos) e produção de diásporos vegetativos (gemas, ápices decíduos, ramos caducos, ramos flageliformes, bulbilhos e gemas rizoidais).

Glime (2007) chama a atenção para os conceitos de propágulos e gemas; propágulos seriam definidos como estruturas que apresentam célula apical, a qual pode originar diretamente um filídio ou um gametófito, sem ocorrência do estádio protonemal, enquanto que gemas seriam definidas como estruturas sem célula apical e que sempre iniciam o desenvolvimento de novos gametófitos a partir de protonemas. Esses conceitos, no entanto, não serão aqui adotados, uma vez que, às vezes, propágulos podem formar protonemas, como afirma a própria Glime (2007). Propágulos, aqui, serão tomados no seu sentido amplo, como unidades de dispersão oriundas de um processo assexuado.

Os processos de reprodução vegetativa (s.l.) estão amplamente distribuídos entre os membros de Lejeuneaceae, mesmo naquelas espécies que estão com esporófito formado, significando uma estratégia que permite tanto a variabilidade genética através do fluxo gênico à custa da reprodução sexuada, quanto a rápida colonização e ocupação do habitat pelo processo de propagação vegetativa.

Pela análise da tabela 1, verifica-se que o padrão mais comum de reprodução vegetativa foi filídios caducos, que ocorreu 11 vezes, seguido de formação de gemas discóides (nove vezes) e de gemas talóides alongadas ou irregulares (sete vezes). Foram observados filídios caducos em Cheilolejeunea rigidula, para a qual ainda não tinham sido referidos. Em Rectolejeunea flagelliformis, os filídios caducos são morfologicamente diferentes dos persistentes, em geral portando rizóides ou dentes pluricelulares na margem. A presença de rizóides em filídios pode ocorrer mesmo naqueles persistentes, como observado em Cheilolejeunea adnata, em geral os mais velhos, prestes a serem destacados, fato também comum em alguns musgos.

Gemas discóides foram mais freqüentes nos táxons neotênicos (subfamília Cololejeuneoideae, senso Schuster 1980). As gemas, geralmente, são dispersas a pouca distância da planta que lhe deu origem, aumentando o número de indivíduos na população, favorecendo o crescimento da assembléia e ocupando maior extensão do substrato. Algumas gemas, no entanto, como aquelas produzidas por espécies de Aphanolejeunea, Colura, Cololejeunea e Diplasiolejeunea, podem ser dispersas por distâncias mais longas através do vento, ou presas a 
algum pequeno invertebrado e, assim, ocuparem outros habitats, propiciando a proliferação de indivíduos geneticamente idênticos (clones). Esses indivíduos podem entrar em contato com outros de diferentes populações, favorecendo o fluxo gênico entre populações espacialmente afastadas (Schuster 1980). Esse fato pode ser um dos motivos para o grande número de táxons com ampla distribuição, não só no paleotrópico e neotrópico, como também em outras regiões biogeográficas.

Fragmentação de ramos (formação de cládios) e de filídios foram os padrões menos comuns, enquanto que a produção de regenerantes foi relativamente comum, tendo ocorrido cinco vezes. Os regenerantes tanto podem ser formados nos filídios caducos quanto nos persistentes.

Observa-se, também, que algumas espécies apresentaram mais de um padrão de reprodução vegetativa, como Ceratolejeunea cornuta (regenerantes e gemas), Cheilolejeunea rigidula (filídos caducos e regenerantes), Lejeunea maxonii (filídios caducos e regenerantes), Lejeunea phyllobola (filídios caducos e regenerantes) e Lejeunea tapajosensis (filídios caducos e regenerantes).

A ocorrência abundante de processos de reprodução vegetativa em Lejeuneaceae, principalmente por filídios caducos, com ou sem regenerantes, é um fato que pode explicar a sua capacidade de colonizar diversos substratos e sua ampla distribuição, bem como o seu predomínio em florestas tropicais úmidas, frente às outras famílias de hepáticas. Essa estratégia reprodutiva permite formar, de um modo mais rápido e com baixo custo energético, maior número de gametófitos e, conseqüentemente, explorar melhor os recursos do ambiente, além de propiciar maior poder dispersivo, ampliando a área de distribuição do táxon, sem o custo energético do processo sexuado. Nos táxons neotênicos da Tribo Lejeuneeae esse processo é bem característico, com abundante formação de gemas discóides que são formadas em determinadas regiões da lâmina ou margem do lobo dos filídios, mesmo em gametófitos com esporófito desenvolvido. A abundante formação de gemas nesse grupo pode ser uma resposta à alta instabilidade do substrato que comumente colonizam (folhas vivas), e esse fato também explica a ocorrência de neotenia, verificada pelo padrão pendular (em zig-zag) de segmentação do merófito, padrão este observado nos estádios iniciais da formação de ramos (Schuster 1980, Gradstein et al. 2006).

Tem sido muito comum o uso dos processos de reprodução vegetativa como critério taxonômico para separação de espécies ou mesmo na circunscrição de gêneros. Nos gêneros Radula e Lejeunea, por exemplo, a reprodução vegetativa por filídios caducos é usada como critério para separar grupos de espécies. $\mathrm{Na}$ circunscrição de Rectolejeunea a reprodução vegetativa por filídos caducos foi um forte critério utilizado tanto por Evans (1906) quanto por Schuster (1980, 2000).

Os processos de reprodução vegetativa por serem bastante comuns e ocorrerem em diversos táxons não estreitamente relacionados, não são úteis para se estabelecerem relações filogenéticas e o seu uso como critério taxonômico diagnóstico deve ser feito com cautela, embora seja uma importante característica de certas espécies. Também não é adequado afirmar-se que em um determinado táxon esses processos não ocorram, apesar de não terem sido observados.

Agradecimentos - $\mathrm{O}$ autor é especialmente grato aos curadores dos Herbários CEPEC, HUEFS, SP, NY, G, a Silvana Vilas Bôas-Bastos, pela confecção das ilustrações, e aos revisores por suas sugestões.

\section{Referências bibliográficas}

EVANS, A. 1906. Hepaticae of Puerto Rico. IV. Cheilolejeunea, Rectolejeunea, Cystolejeunea and Pycnolejeunea. Bulletin of the Torrey Botanical Club 31:183-226.

FULFORD, M. 1944. Sporeling and vegetative reproduction in the genus Ceratolejeunea. Bulletin of the Torrey Botanical Club 71:638-654.

GLIME, J.M. 2007. Bryophyte Ecology. Vol. 1. Physiological Ecology. Michigan Technological University and the International Association of Bryologists. http:// www.bryoecol.mtu.edu (acesso em 26/10/2007).

GRADSTEIN, S.R. 1994. Lejeuneaceae: Ptychanthoideae, Brachiolejeuneae. Flora Neotropica, Monograph 62: 1-216.

GRADSTEIN, S.R. \& D.P. COSTA. 2003. Liverworts and hornworts of Brazil. Memoirs of the New York Botanical Garden 87:1-301.

GRADSTEIN, S.R., WILSON, R., ILKIU-BORGES, A.L. \& HEINRICHS, J. 2006. Phylogenetic relationships and neotenic evolution of Metzgeriopsis (Lejeuneaceae) based on chloroplast DNA sequences and morphology. Botanical Journal of the Linnean Society 151:293-308.

HOLMGREN, P.K., HOLMGREN, N.H. \& BARNETT, L.C. 1990. Index herbariorum, part I. The Herbaria of the world. New York Botanical Garden, New York.

KIMMERER, R.W. 1991. Reproduction ecology of Tetraphis pellucidus II. Differential success of sexual and asexual propagules. The Bryologist 94:248-288.

KIMMERER, R.W. 1994. Ecological consequences of sexual versus asexual reproductions in Dicranum flagellare and Tetraphis pellucidus. The Bryologist 97:20-25.

LAAKA-LINDBERG, S. 1999. Asexual reproduction in a population of a leafy hepatic species Lophozia silvicola Buch in central Norway. Plant Ecology 141:137-144. 
LAAKA-LINDBERG, S. 2000. Substrate preference and reproduction in Lophozia silvicola (Hepaticopsida) in Southern Finland. Annales Botanici Fennici 37:85-93.

LONGTON, R.E. \& SCHUSTER, R.M. 1983. Reproductive Biology. In New Manual of Bryology (R.M. Schuster, ed.). Hattori Botanical Laboratory, Nichinan, p.386-462.

MARTIN, V. 2001. Gemmae on leaves and other observations regarding Bryum flaccidus Brid. Evansia 18:31-39.

MISHLER, B. 1988. Reproduction ecology of Bryophytes. In The reproductive ecology: patterns and strategies (J. Lovet \& L.L. Doust, eds.). Oxford University Press, Oxford, p.285-305.

NEWTON, A.E. \& MISHLER, B.D. 1994. The evolutionary significance of asexual reproduction in mosses. Journal of the Hattori Botanical Laboratory 76:127-145.

NORDHORN-RICHTER, G. 2004. Bryophytes with asexual reproduction - their ability to succeed in an industrial area. Oecologia 54:391-400.

PFEIFFER, T., FRITZ, S., STECH, M. \& FREY, W. 2006. Vegetative reproduction and clonal diversity in Rhytidium rugosum (Rhytidiaceae, Bryopisda) inferred by morpho-anatomical and molecular analyses. Journal of Plant Research 119:125-135.
REINER-DREHWALD, M.E. 1994. Sobre Microlejeunea globosa (Spruce) Steph. y la fragmentación del tallo, un tipo de reproducción asexual poco conocido en hepáticas. Candollea 49:225-232.

REESE, W.D. 1997. Asexual reproduction in Calymperaceae (Musci), with special reference to functional morphology. Journal of the Hattori Botanical Laboratory 82:227-244.

REESE, W.D. 2001a. The gemmae of the Calymperaceae. The Bryologist 104:282-289.

REESE, W.D. 2001b. Gemmipars in the Calymperaceae. The Bryologist 104:299-302.

ROADS, E. \& LONGTON, R.E. 2003. Reproductive biology and population studies in two annual shuttle mosses. Journal of the Hattori Botanical Laboratory 93:305-318.

SCHUSTER, R.M. 1980. Hepaticae and Anthocerotae of North America east Handredht Meridian. Columbia University Press, New York.

SCHUSTER, R.M. 1988. Ecology, reproductive biology and dispersal of Hepaticae in the tropics. Journal of the Hattori Botanical Laboratory 64:237-269.

SCHUSTER, R.M. 2000. Studies on Lejeuneaceae II. Rectolejeunea Evs. emend. Schust. (Lejeuneoideae). Journal of the Hattori Botanical Laboratory 89:113-150. 